\title{
A Floating Sleeve Antenna Yields Localized Hepatic Microwave Ablation
}

\author{
Deshan Yang, Student Member, IEEE, John M. Bertram, Member, IEEE, Mark C. Converse, Member, IEEE, \\ Ann P. O'Rourke, John G. Webster*, Life Fellow, IEEE, Susan C. Hagness, Senior Member, IEEE, James A. Will, and \\ David M. Mahvi
}

\begin{abstract}
We report a novel coaxial antenna for hepatic microwave ablation. This device uses a floating sleeve, that is, a metal conductor electrically isolated from the outer connector of the antenna coaxial body, to achieve a highly localized specific absorption rate pattern that is independent of insertion depth. This floating sleeve coaxial dipole antenna has low power reflection in the 2.4-GHz IMS band. Ex vivo experiments confirm our numerical simulation results.
\end{abstract}

Index Terms-Ablation, coaxial aperture antennas, finite element methods, floating sleeve, microwave heating.

\section{INTRODUCTION}

$\mathbf{M}$ ICROWAVE ABLATION (MWA) is a promising technology for the treatment of hepatic tumors. The goal of MWA is to destroy the tumor along with a $1 \mathrm{~cm}$ margin of normal hepatic tissue. This technology has been used in both intraoperative and percutaneous approaches for primary hepatocellular carcinoma and hepatic metastasis of colorectal carcinoma [1]-[3]. Hepatic tumors are commonly spherically shaped and range in size from less than $1 \mathrm{~cm}$ to larger than 10 $\mathrm{cm}$ in diameter. However, current technology limits a single ablated region to approximately $3 \mathrm{~cm} \mathrm{[4]-[8],} \mathrm{not} \mathrm{large} \mathrm{enough}$ to treat large tumors in a single pass. When the input power is increased to ablate larger regions, undesired heating occurs along the coaxial feedline of the antenna. This detrimental heating causes damage to the liver outside the desired treatment region and can lead to burning of the skin during percutaneous treatment.

There are three potential causes of detrimental heating along the coaxial feedline. First, any impedance mismatch between the antenna and the surrounding medium will create reflections that set up standing waves within the coaxial feedline. Under such conditions, the local currents on the inside of the outer conductor can become large enough to cause local heating. If the wall of the outer conductor is thin, the heat may transfer

Manuscript received January 8, 2005; revised June 28, 2005. This work was supported by the National Institute of Health (NIH) under Grant DK58839. Asterisk indicates corresponding author.

D. Yang and S. C. Hagness are with the Department of Electrical and Computer Engineering, University of Wisconsin, Madison, WI 53706 USA.

J. M. Bertram is with the Department of Biomedical Engineering, University of Wisconsin, Madison, WI 53706 USA

M. C. Converse, A. P. O'Rourke, and D. M. Mahvi are with the Department of Surgery, University of Wisconsin, Madison, WI 53792 USA.

*J. G. Webster is with the Department of Biomedical Engineering, University of Wisconsin, 1550 Engineering Drive, Madison, WI 53706 USA (e-mail: webster@engr.wisc.edu).

J. A. Will is with the Department of Animal Health and Biomedical Sciences, University of Wisconsin, Madison, WI 53706 USA.

Digital Object Identifier 10.1109/TBME.2005.869794 to the surrounding tissue. Second, an impedance mismatch between the antenna and surrounding medium may also result in unbalanced currents on the inner and outer conductors of the coaxial feed. In this case, a remainder current flows along the outside of the outer conductor of the coaxial feedline. The 'tail' seen in many of the specific absorption rate (SAR) patterns computed from simulations of MWA antennas is attributed to this current flow. Finally, most antenna designs are based upon copper coaxial cables. Since copper is a good thermal conductor, heat generated near the distal tip may be conducted along the feedline.

Several types of coaxial-based antennas, including the coaxial slot antenna [9], coaxial dipole antenna [10], coaxial monopole antenna [11], coaxial cap-choke antennas [12], [13], and others [14]-[17] have been designed for MWA or microwave hyperthermia therapies in an attempt to prevent this backward heating while creating as large an ablation radius as possible. The cap-choke antenna seems to most efficiently prevent backward heating [12], [18]. Cap-choke antennas offer a localized SAR pattern and the smallest SAR tail. A cap-choke antenna uses a metal sleeve, usually one-fourth of a wavelength long, soldered to the outer connector as a choke, and an extra metal ring at the distal tip of the antenna as a cap. This antenna works well at lower power levels, but the residual SAR tail of the antenna increases in size and causes backward heating problems at higher power levels or during extended ablations. At high microwave input power levels, even low-level backward heating is detrimental enough to cause damage to normal hepatic tissue, as well as serious skin burning during percutaneous ablation.

This paper presents a novel coaxial antenna design, the floating sleeve antenna, which addresses many of the critical problems with current MWA antennas.

\section{Design of the Floating SleEve Antenna}

Our goal was to design a coaxial antenna with a highly localized SAR pattern and low reflectivity for higher power transmission. Fig. 1 shows the design of the floating sleeve antenna. The antenna is based on a $50-\Omega$ UT- 085 semirigid copper-Teflon coaxial cable. A standard coaxial dipole antenna [10] is constructed from the coaxial cable and tightly wrapped with thin layers of Teflon tape. The metal sleeve, which is comprised of a section of copper tube (3.2-mm outer diameter, 2.5-mm inner diameter), is slid onto the Teflon-coated coaxial dipole antenna and positioned behind the antenna slot. The whole antenna assembly is then tightly wrapped with Teflon tape. The Teflon tape is heated during and after wrapping in order to prevent air from being trapped in the tape layers. Fig. 1(a) shows the longitudinal 


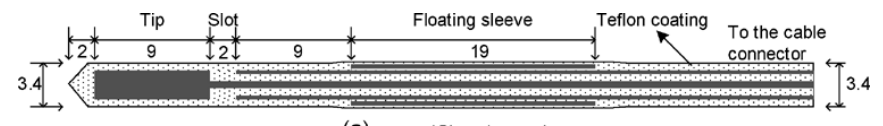

(a) Dimensions are in $\mathrm{mm}$

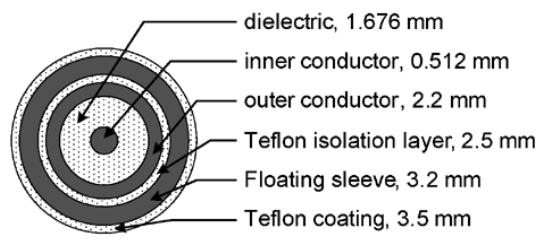

(b)

Fig. 1. (a) Schematic of the floating sleeve antenna and (b) cross section of the antenna at the sleeve.

dimensions of each section of the antenna along with the overall diameter, while Fig. 1(b) shows the interior diameters in the region of the sleeve.

The floating sleeve antenna differs from existing laboratory and clinical devices (such as the cap-choke antenna) in that the sleeve is electrically isolated from the outer conductor of the coaxial feedline. This floating sleeve is similar to the open sleeve antenna [17] which also uses a floating sleeve. However the floating sleeve of the open sleeve antenna in [17] is quite long.

We designed the floating sleeve using computer simulations once we gained a qualitative understanding of the importance and effect of the following design parameters: length of the sleeve, thickness of Teflon layer above the sleeve, thickness of Teflon isolation layer, and width of antenna slot and length of antenna tip.

We determined that the SAR pattern is affected by both the length of the sleeve and the thickness of the Teflon layer. If the sleeve is not covered by a Teflon layer, it needs to be approximately half of the effective wavelength in liver tissue. If the sleeve is covered by a Teflon layer, the sleeve needs to be longer, with the length depending on the thickness of the Teflon layer. This length is critical, and if significantly longer or shorter than the ideal length, the sleeve can be less effective than other reported antenna designs. As long as the sleeve is half a wavelength (adjusted for the presence of Teflon) in length and is not covering the antenna slot, it seems able to constrain the tail of the SAR pattern. In fact the edge of the SAR pattern seems tied to the termination of the sleeve, to the extent that by sliding the floating sleeve, we can control and change the SAR pattern from a spherical shape to an elliptical shape. This may make it possible to control the shape of the lesion to fit different tumor shapes. The thickness of the Teflon isolation layer (the Teflon layer between the floating sleeve and the outer conductor of the coaxial cable) does not seem to affect the SAR pattern as long as it is at least $0.1 \mathrm{~mm}$.

Our design uses a 2-mm-wide slot, which is easily fabricated, and also gives minimal power reflection. The length of the antenna tip also slightly affects the power reflection and shape of the SAR pattern. The length was adjusted to give a good trade off between the power reflection and a spherical SAR pattern.

The antenna design reported here is based on commercially available coaxial cable and utilizes readily available and inexpensive construction materials. This easily fabricated antenna is suitable for open or laproscopic operative therapies. However, the diameter of $3.5 \mathrm{~mm}$ precludes its use in percutaneous therapies.

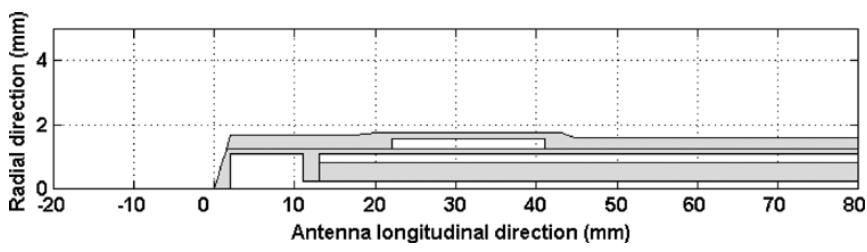

Fig. 2. Axi-symmetric CEM model in the vicinity of the tip of the floating sleeve antenna. The vertical axis ( $r$ axis) corresponds to the radial direction while the horizontal axis ( $z$ axis) corresponds to the longitudinal axis of the antenna. The aspect ratio used in this diagram is nonphysical in order to show the details in the radial direction.

\section{COMPUTER Simulation AND EXPERIMENTAL RESUltS}

We used computational electromagnetics simulations to compute the SAR distribution and input reflection coefficient, or $S_{11}$, as a function of frequency for the proposed antenna design. We compared simulated $S_{11}$ to experimentally measured $S_{11}$ to validate the model, and evaluated lesion size and shape after ex vivo ablation.

\section{A. The Computational Electromagnetics (CEM) Model}

We performed simulations of the floating sleeve antenna using the electromagnetic modeling capabilities of FEMLAB version 2.3. We used an axially symmetric model [19], which minimized the computation time while maintaining good resolution and the full three-dimensional nature of the fields. The two-dimensional axisymmetric model requires $180 \mathrm{MB}$ memory and $50 \mathrm{~s}$ of CPU time for each FEMLAB simulation on an Intel P4 2.8-GHz desktop computer. Fig. 2 shows the structure of the floating sleeve antenna near the tip in our CEM model. The model assumes that the floating sleeve antenna is immersed in homogeneous bovine liver tissue. The horizontal $z$ axis is oriented along the longitudinal axis of the antenna and the vertical $r$ axis is oriented along the radial direction. The computational domain corresponds to a physical domain size of $60 \mathrm{~mm}$ in radius and $110 \mathrm{~mm}(z=-30 \mathrm{~mm}$ to $z=80 \mathrm{~mm})$ in length, surrounded by air.

The dielectric insulator of the coaxial cable, the antenna slot and the outer coating materials are all Teflon with relative permittivity equal to 2.1 . The relative permittivity and conductivity of liver tissue at $37{ }^{\circ} \mathrm{C}$ are $\varepsilon_{\mathrm{r}}=43.03$ and $\sigma=1.69 \mathrm{~S} / \mathrm{m}$, respectively, at $2.45 \mathrm{GHz}$. These values were obtained using a 4-pole Cole-Cole equation (shown below) with coefficients for liver from [20]

$$
\hat{\varepsilon}(\omega)=\varepsilon_{\infty}+\sum_{n=1}^{4} \frac{\Delta \varepsilon_{n}}{1+\left(j \omega \tau_{n}\right)^{1-\alpha_{n}}}+\frac{\sigma_{\mathrm{i}}}{j \omega \varepsilon_{0}} .
$$

Here, $\omega$ is the angular frequency [rad], $\hat{\varepsilon}$ is the effective complex relative permittivity and $\varepsilon_{0}$ is the permittivity of free space. Table I gives all other parameters of (1). The effective wavelength in liver tissue is approximately $18.5 \mathrm{~mm}$.

The SAR [W/kg] in tissue is calculated as a function of position as follows:

$$
\mathrm{SAR}=\frac{\sigma|\bar{E}|^{2}}{(2 \rho)}
$$

where $\sigma$ is the tissue conductivity $[\mathrm{S} / \mathrm{m}]$ at the excitation frequency, $\rho$ is the tissue density $\left[\mathrm{kg} / \mathrm{m}^{3}\right]$, and $\bar{E}$ is the spatially dependent time-harmonic electric field vector $[\mathrm{V} / \mathrm{m}]$. 
TABLE I

4 Pole Cole-Cole CoEFFicients for Liver From [20]

\begin{tabular}{cccc}
\hline \hline Parameter & Value & Parameter & Value \\
\hline$\varepsilon_{\infty}$ & 4.0 & $\sigma_{\mathrm{i}}$ & 0.0200 \\
$\Delta \varepsilon_{1}$ & 39.0 & $\Delta \varepsilon_{2}$ & 6000 \\
$\tau_{1}(\mathrm{ps})$ & 8.84 & $\tau_{2}(\mathrm{~ns})$ & 530.52 \\
$\alpha_{1}$ & 0.10 & $\alpha_{2}$ & 0.20 \\
$\Delta \varepsilon_{3}$ & $5.0 \times 10^{4}$ & $\Delta \varepsilon_{4}$ & $3.0 \times 10^{7}$ \\
$\tau_{3}(\mu \mathrm{s})$ & 22.74 & $\tau_{4}(\mathrm{~ms})$ & 15.915 \\
$\alpha_{3}$ & 0.20 & $\alpha_{4}$ & 0.05 \\
\hline \hline
\end{tabular}

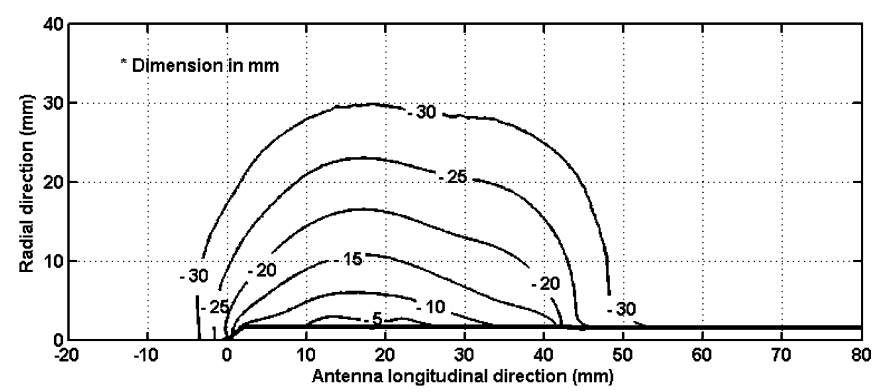

Fig. 3. Plot of normalized SAR on a dB scale. The SAR values are normalized to the maximum SAR value in the simulation region. For reference, the probe tip is at $z=0 \mathrm{~mm}$, the slot is centered at $z=12 \mathrm{~mm}$, and the sleeve begins at $z=22 \mathrm{~mm}$ and extends to $z=41 \mathrm{~mm}$. The region of the simulated liver tissue is from $z=-23$ to $z=83 \mathrm{~mm}$ horizontally and $r=0$ to $r=60 \mathrm{~mm}$ vertically. The boundary of the region of the liver tissue is not shown in the figure so SAR pattern near the antenna slot can be shown in better details. The antenna is inserted $70 \mathrm{~mm}$ deep into the liver, from the center of the antenna slot at $z=23 \mathrm{~mm}$ to liver tissue right side boundary at $z=83 \mathrm{~mm}$.

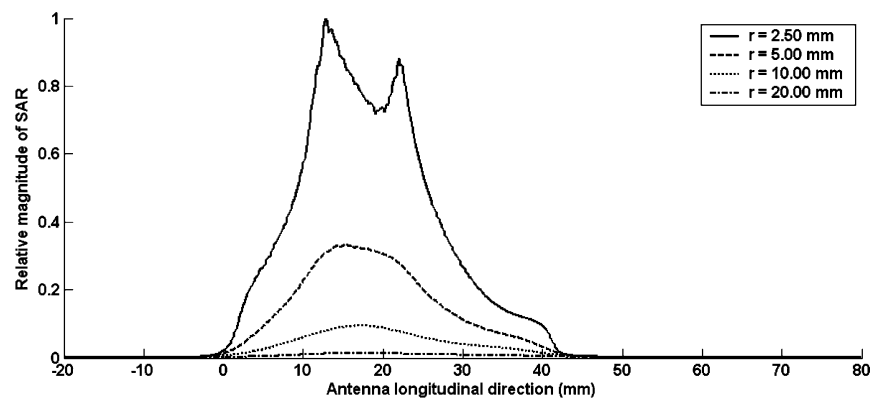

Fig. 4. Plot of normalized SAR on linear scale as a function of $z$, at constant values of $r=2.5,5.0,10.0$, and $20.0 \mathrm{~mm}$. The SAR values are normalized to the maximum value in the plot.

Fig. 3 shows the SAR pattern, normalized to the maximum value in the simulation region, in dB. Fig. 4 shows normalized SAR values along the longitudinal direction at a number of different radial positions. Figs. 3 and 4 indicate that the antenna SAR pattern is completely constrained by the sleeve and is localized in the region from the antenna tip to the end of the floating sleeve. To test the effect of the insertion depth on the SAR pattern, Fig. 5 shows the SAR pattern when the active components of the antenna are near the surface. It shows that the localization of the SAR pattern is relatively independent of the insertion depth as long as the sleeve is completely immersed in the liver.

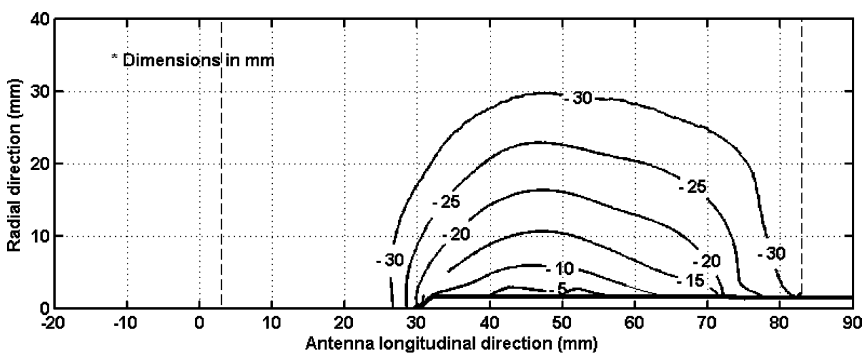

Fig. 5. Plot of normalized SAR on a dB scale. Comparing to Fig. 3, the antenna is inserted $40 \mathrm{~mm}$ deep into the liver, from the center of the antenna slot at $z=43 \mathrm{~mm}$ to liver tissue right side boundary at $z=83 \mathrm{~mm}$. Boundaries of simulated liver tissue region are marked in dashed lines.

\section{B. Frequency Sweep for Antenna Power Reflection}

To validate our model as well as examine the power reflection characteristics of this antenna design, we fabricated an antenna and measured its reflection coefficient $\left(S_{11}\right)$ spectrum, in fresh bovine liver, from 0.5 to $10 \mathrm{GHz}$ using a vector network analyzer (Agilent E8364A). We revised the simulated antenna dimensions to match the exact fabricated dimensions and computed the $S_{11}$ spectrum at discrete frequencies from $0.5 \mathrm{GHz}$ to $10 \mathrm{GHz}$. At each discrete frequency, we adjusted the dielectric properties of bovine liver tissue based on (1).

Fig. 6 shows that the measured and computed results agree quite well. Fig. 6 shows that the antenna's minimum reflection is near $2 \mathrm{GHz}$, not the desired frequency of $2.45 \mathrm{GHz}$. The result is not unexpected as the antenna was not designed to minimize the reflected power, but to obtain a good SAR pattern while maintaining a reasonably low reflection coefficient. The measured $S_{11}$ is $-17.1 \mathrm{~dB}$ and the simulated $S_{11}$ is $-18 \mathrm{~dB}$ at $2.45 \mathrm{GHz}$ and we believe these are acceptably low for this initial design. Further optimization of the antenna could reduce this reflection further and permit tuning the null to $2.45 \mathrm{GHz}$. We note, however, that a small degree of detuning is expected in practice as the dielectric properties change during ablation.

\section{Ex Vivo Experiments and Results}

Ultimately it is the coagulated region produced by an antenna that determines its effectiveness so we performed ex vivo ablations. We connected the floating sleeve coaxial antenna to a CoberMuegge MG0300D $300 \mathrm{~W}, 2.45-\mathrm{GHz}$ microwave generator through a $1 \mathrm{~m}$ long flexible coaxial cable. We then carefully inserted the antenna into peripheral regions of fresh bovine liver to avoid heating near the largest blood vessels. We then heated the liver using $120 \mathrm{~W}$ of power for $150 \mathrm{~s}$ monitoring and recording input and reflected power. Initial liver temperature was $37^{\circ} \mathrm{C}$. We note that $120 \mathrm{~W}$ is within the power handling capabilities of the UT-085 coaxial cable used.

After each experiment we sliced the liver tissues into either longitudinal cross sections or transverse cross sections. For longitudinal slicing, we placed a probe into the track created by the antenna and made a longitudinal transection of the lesion close to the inserted probe. We photographed tissue slices using a ruler for reference and scanned using an HP ScanJet 3970 scanner at 200 dpi or higher resolution. Fig. 7 shows one of the ex vivo experiment results. Here, the lesion size is approximately $5.6 \times$ $3.7 \mathrm{~cm}$, when measured to the periphery of the "white zone." This is a slightly different shape than predicted by the SAR pattern. The procedure of the thermal lesion formation is a complex 


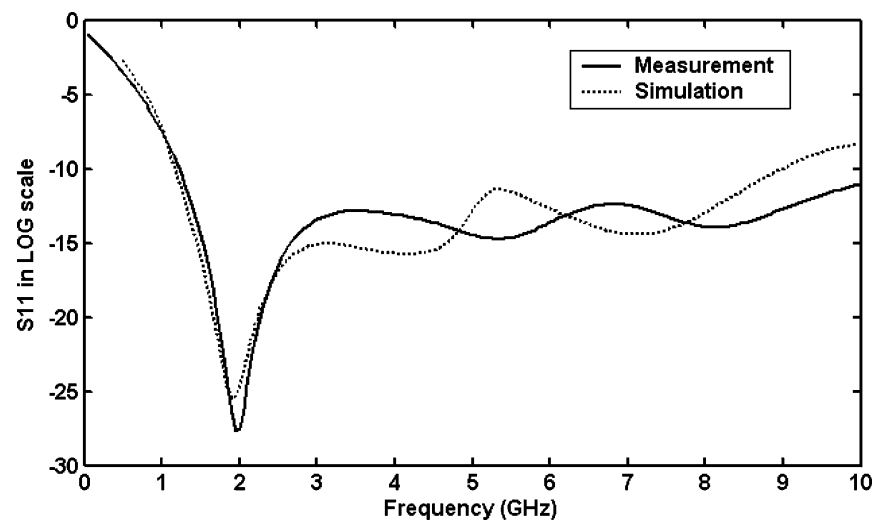

Fig. 6. Input reflection coefficient $\left(S_{11}\right)$ for the floating sleeve antenna versus frequency.

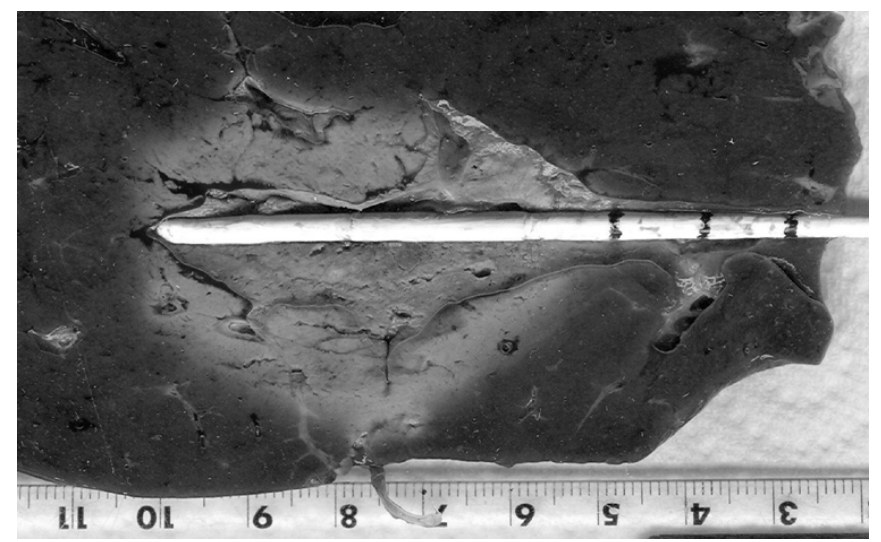

Fig. 7. Photo of ablated bovine liver tissue. The lesion was created by applying $120 \mathrm{~W}$ for $150 \mathrm{~s}$. The initial temperature of liver tissue was about $37^{\circ} \mathrm{C}$. The spacing between the markers on the antenna body was $1 \mathrm{~cm}$. The lesion was about $5.6 \times 3.7 \mathrm{~cm}$ and clearly localized to the active radiation region of the antenna. The lesion size was comparable to large lesion size reported by Strickland et al. [21].

combination of microwave energy absorption, heating conduction as well as possible tissue water evaporation, condensation and movement during the ablation period. Therefore the SAR pattern is only expected to be a guide to final lesion shape. The lesion does show a very well constrained tail as predicted by the SAR pattern. We created 16 lesions using $120 \mathrm{~W}$ of power for $150 \mathrm{~s}$, to examine repeatability, mean and std deviation Size of the lesions were $5.87 \pm 0.32 \mathrm{~cm}$ by $3.64 \pm 0.33 \mathrm{~cm}$.

\section{DisCUSSION AND CONCLUSION}

Currently, the major limitation of MWA in treating larger liver tumors is the inability to deliver sufficient power to the tumor while minimizing detrimental heating to normal liver tissue outside the treatment region. We have developed a novel floating sleeve coaxial antenna for microwave liver tumor ablation, using both simulation and experimental measurements. This antenna is capable of providing very localized power deposition in hepatic tissue with minimal backward heating; as well as low power reflection, and high power throughput. The significant new feature of this antenna is the floating sleeve used to prevent the flow of electromagnetic energy along the coaxial applicator. The critical parameter seems to be the length of the sleeve. One other feature of this sleeve is its apparent ability to constrain the SAR pattern to the end of the sleeve allowing a certain amount of control over the shape of the SAR pattern.

While this study has yielded a qualitative understanding of the importance and effect of the parameters of the sleeve, more studies are currently being performed to identify the reason for the superior performance of the floating sleeve in constraining the tail of the SAR pattern.

\section{ACKNOWLEDGMENT}

The authors would like to thank D. Haemmerich for his contribution in this study.

\section{REFERENCES}

[1] G. D. Dodd, M. C. Soulen, R. A. Kane, T. Livraghi, W. R. Lees, Y. Yamashita, A. R. Gillams, O. I. Karahan, and H. Rhim, "Minimally invasive treatment of malignant hepatic tumors: at the threshold of a major breakthrough," Radiographics, vol. 20, pp. 9-27, 2000.

[2] C. Erce and R. W. Parks, "Interstitial ablative techniques for hepatic tumors," Br. J. Surg., vol. 90, pp. 272-289, 2003.

[3] S. Gaiani, N. Celli, L. Cecilioni, F. Piscaglia, and L. Bolondi, "Percutaneous treatment of hepatocellular carcinoma," Aliment Pharmacol. Ther, vol. 17, pp. 103-110, 2003.

[4] T. Shibata, Y. Limuro, Y. Yamamoto, and Y. Maetani, "Small hepatocellular carcinoma: comparison of radio-frequency ablation and percutaneous microwave coagulation therapy," Vasc. Interventional Radiol., vol. 223, pp. 331-337, 2002.

[5] M. D. Lu, J. W. Chen, X. Y. Xie, L. Liu, X. Q. Huang, L. J. Liang, and J. F. Huang, "Hepatocellular carcinoma: US-guided percutaneous microwave coagulation therapy," Radiology, vol. 221, pp. 167-172, 2001.

[6] T. Seki, M. Wakabayashi, T. Nakagawa, T. Itho, T. Shiro, K. Kunieda, M. Sato, S. Uchiyama, and K. Inoue, "Ultrasonically guided percutaneous microwave coagulation therapy for small hepatocellular carcinoma," Cancer, vol. 74, pp. 817-825, 1994.

[7] A. Wright, F. T. Lee, and D. M. Mahvi, "Hepatic microwave ablation with multiple antennae results in synergistically larger zones of coagulation necrosis," Ann. Surg. Oncol., vol. 10, pp. 275-283, 2003.

[8] B. Dong, P. Liang, X. Yu, L. Su, D. Yu, Z. Cheng, and J. Zhang, "Percutaneous sonographically guided microwave coagulation therapy for hepatocellular carcinoma: results in 234 patients," Am. J. Roentgenol., vol. 180, pp. 1547-1555, 2003.

[9] K. Saito, Y. Hayashi, H. Yoshmura, and K. Ito, "Numerical analysis of thin coaxial antennas for microwave coagulation therapy," in Proc. IEEE Antennas Propagation Soc. Int. Symp., vol. 2, 1999, pp. 992-995.

[10] W. Hurter, F. Reinbold, and W. J. Lorenz, "A dipole antenna for interstitial microwave hyperthermia," IEEE Trans. Microw. Theory Tech., vol. 39, no. 6, pp. 1048-1054, Jun. 1991.

[11] S. Labonte, A. Blais, S. R. Legault, H. O. Ali, and L. Roy, "Monopole antennas for microwave catheter ablation," IEEE Trans. Microw. Theory Tech., vol. 44, no. 10, pp. 1832-1840, Oct. 1996.

[12] S. Pisa, M. Cavagnaro, P. Bernardi, and J. C. Lin, "A 915-MHz antenna for microwave thermal ablation treatment: physical design, computer modeling and experimental measurement," IEEE Trans. Biomed. Eng., vol. 48, no. 5, pp. 599-601, May 2001.

[13] J. C. Lin and Y. J. Wang, "The cap-choke catheter antenna for microwave ablation treatment," IEEE Trans. Biomed. Eng., vol. 43, no. 6, pp. 657-660, Jun. 1996.

[14] R. D. Nevels, G. D. Arndt, G. W. Raffoul, J. R. Carl, and A. Pacifico, "Microwave catheter design," IEEE Trans. Biomed. Eng., vol. 45, no. 7, pp. 885-890, Jul. 1998.

[15] C. L. Brace, D. W. van der Weide, F. T. Lee, P. F. Laeseke, and L. Sampson, "Analysis and experimental validation of a triaxial antenna for microwave tumor ablation," in IEEE MTT-S Int. Microwave. Symp. Dig., vol. 3, 2004, pp. 1437-1440.

[16] I. Longo, G. B. Gentili, M. Cerretelli, and N. Tosoratti, "A coaxial antenna with miniaturized choke for minimally invasive interstitial heating," IEEE Trans. Biomed. Eng., vol. 50, no. 1, pp. 82-88, Jan. 2003.

[17] K. Ito, M. Hyodo, M. Shimura, and H. Kasai, "Thin applicator having coaxial ring slots for interstitial microwave hyperthermia," in IEEE AP-S Antennas Propagation Soc. Int. Symp. Dig., vol. 3, 1990, pp. 1233-1236.

[18] K. Saito, S. Hosaka, S.-Y. Okabe, H. Yoshimura, and K. Ito, "A proposition on improvement of a heating pattern of an antenna for microwave coagulation therapy: introduction of a coaxial-dipole antenna," Electron. Commun. Japan, pt. I-Communications, vol. 86, pp. 2351-2357, 2003.

[19] (2004) FEMLAB 3.0. COMSOL AB, Stockholm, Sweden. [Online]. Available: http://www.comsol.com 
[20] S. Gabriel, R. W. Lau, and C. Gabriel, "The dielectric properties of biological tissues: III. parametric models for the dielectric spectrum of tissues," Phys. Med. Biol., vol. 41, pp. 2271-2293, 1996.

[21] A. D. Strickland, P. J. Clegg, N. J. Cronin, B. Swift, M. Festing, K. P. West, G. S. M. Robertson, and D. M. Lloyd, "Experimental study of large-volume microwave ablation in the liver," Br. J. Surg., vol. 89, pp. 1003-1007, 2002.

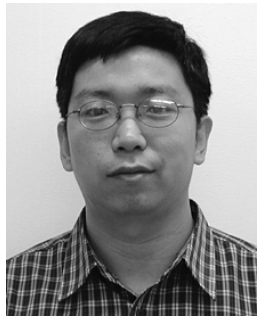

Deshan Yang (S'04-M'05) received the B.S.E.E. degree in June 1992 from the Tsinghua University, Beijing, China. He received the M.S. degree in computer science from Illinois Institute of Technology, Chicago, in Dec. 2001. Since September 2002, he has been working towards the Ph.D. degree in electrical engineering at the University of Wisconsin-Madison. His Ph.D. degree research involves microwave hepatic ablation, measurement of tissue physical responses during heating, computer simulation of electromagnetic fields, and comprehensive heat transfer and tissue water transfers in tissue during heating.

$\mathrm{He}$ worked in software and telecommunications engineering positions for Nokia Telecom, Motorola Inc. and Lucent Technologies from 1995 to 2002. During his graduate studies he was engaged in research in signal processing in biomedical engineering and medical instrumentation.

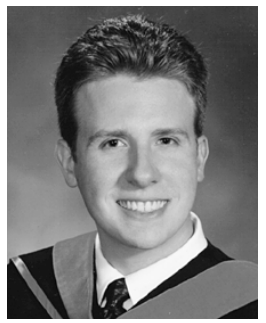

John M. Bertram (S'03-M'05) received the B.S. degree in electrical engineering from the University of Illinois at Urbana-Champaign in 2002. In 2004, he received the M.S. degree in biomedical engineering from the University of Wisconsin-Madison, where his research focused on microwave antenna design for the treatment of liver cancer.

Since January of 2005, he has been employed as a preclinical study director with Medtronic, Inc. in Minneapolis, MN.

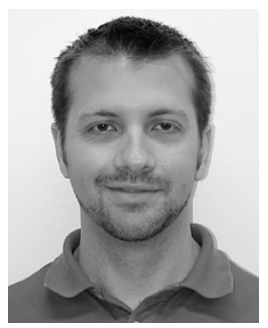

Mark C. Converse (S'91-M'96) received the B.S. degree in electrical engineering in May 1996 from the University of Wisconsin-Madison. He received the M.S. and Ph.D. degrees from the University of Wisconsin-Madison in May 1999 and May 2003, respectively.

During his graduate studies he was engaged in plasma processing research involving damage evaluation/analysis and mitigation during the etching process. After obtaining his M.S. in 1999, he began research in microwave vacuum electronics investigating the impulse response of the helix traveling wave tube. After obtaining the $\mathrm{Ph} . \mathrm{D}$. degree, he began research on projects involving the microwave detection and treatment of breast and liver cancer using microwaves. Currently, he is working as an assistant scientist at the University of Wisconsin. His research interests include electromagnetic interactions with materials, electrical/biological interfaces, and organic electronics.

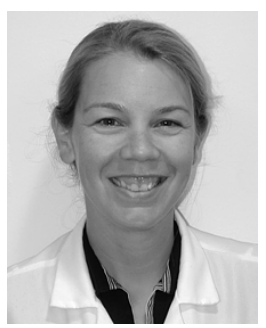

Ann P. O'Rourke received the B.S. degree from Emory University, Atlanta, GA, in 1993 and M.D. degree from the University of Wisconsin-Madison in 2002 .

She is currently a Resident in general surgery and Surgical Oncology Research Fellow at the University of Wisconsin.

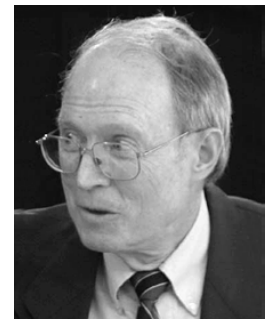

John G. Webster (M'59-SM'69-F'86-LF'97) received the B.E.E. degree from Cornell University, Ithaca, NY, in 1953, and the M.S.E.E. and Ph.D. degrees from the University of Rochester, Rochester, NY, in 1965 and 1967.

$\mathrm{He}$ is Professor Emeritus of Biomedical Engineering at the University of Wisconsin-Madison. In the field of medical instrumentation he teaches undergraduate and graduate courses, and does research on microwave hepatic ablation and safety of electromuscular incapacitation devices.

Dr. Webster is editor of Medical Instrumentation: Application and Design, Third Edition (Wiley, 1998), Encyclopedia of Medical Devices and Instrumentation, Second Edition (Wiley, 2006), Bioinstrumentation (Wiley, 2004) and 20 other books. He is the recipient of the 2001 IEEE-EMBS Career Achievement Award.

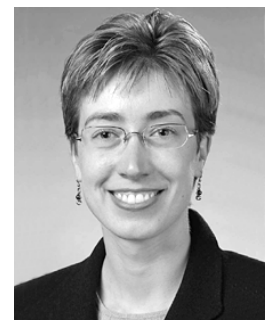

Susan C. Hagness (S'91-M'98-SM'04) received the B.S. degree with highest honors and the Ph.D. degree in electrical engineering from Northwestern University, Evanston, IL, in 1993 and 1998, respectively.

She is currently an Associate Professor in the Department of Electrical and Computer Engineering at the University of Wisconsin-Madison. Her research interests include microwave imaging, sensing, and thermal therapy techniques in biological and medical applications.

Dr. Hagness is an Elected Member of the IEEE AP-S Administrative Committee and an Associate Editor for the IEEE ANTENNAS AND WIRELESS PROPAGation LetTERS. She was the recipient of the Presidential Early Career Award for Scientists and Engineers presented by the White House in 2000. In 2002, she was named one of the 100 top young innovators in science and engineering in the world by the MIT Technology Review magazine. She received the IEEE-EMBS Early Career Achievement Award in 2004

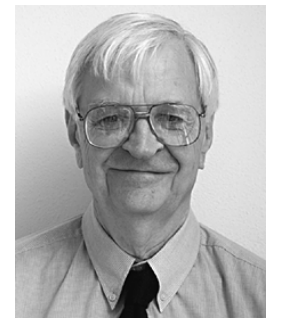

James A. Will received the B.S. and M.S. degrees from University of Wisconsin-Madison in 1952 and 1953, and the DVM degree from Kansas State University, Manhattan, in 1960. After private practice for 4 years he returned to the University of WisconsinMadison where he received the Ph.D. degree in 1967.

$\mathrm{He}$ is Professor Emeritus of Veterinary Medicine, SVM, Surgery, Medical School, Biomedical Engineering, $\mathrm{COE}$ and Animal Science (CALS), the University of Wisconsin-Madison. He teaches cardiovascular and renal physiology to undergraduate and graduate students and is involved with assisting in the biological training of graduate students in biomedical engineering. He is currently doing experimental surgery research in the development of devices for hepatic tumor ablation.

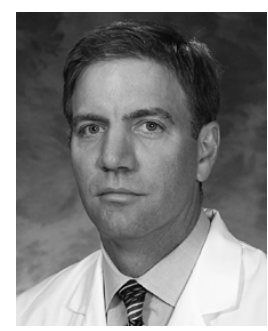

David M. Mahvi attended the University of Oklahoma, Norman, and subsequently received the M.D degree in 1981 from the Medical University of South Carolina, Charleston. He then completed the following postgraduate medical clinical training programs at Duke University, Durham, NC: residency in surgery from 1981-1983; fellowship in immunology 1983-1985; residency in surgery 1985-1989.

In 1989 he joined the Section of Surgical Oncology, Department of Surgery at the University of Wisconsin-Madison where he is now Professor of Surgery and chief of the section. He is also a member, University of Wisconsin Comprehensive Cancer Center. 